\title{
Letter \\ Medical emergency teams and rapid response triggers - the ongoing quest for the 'perfect' patient safety system
}

Philip F Stahel ${ }^{1}$ and Philip S Mehler ${ }^{2}$

\author{
1Department of Orthopaedic Surgery, and Department of Neurosurgery, Denver Health Medical Center, University of Colorado Denver, School of \\ Medicine, Bannock Street, Denver, CO 80204, USA \\ ${ }^{2}$ Department of Patient Safety and Quality, and Department of Internal Medicine, Denver Health Medical Center, University of Colorado Denver, School \\ of Medicine, Bannock Street, Denver, Denver, CO 80204, USA
}

Corresponding author: Philip F Stahel, philip.stahel@dhha.org

Published: 9 October 2009

Critical Care 2009, 13:420 (doi:10.1186/cc8052)

This article is online at http://ccforum.com/content/13/5/420

(c) 2009 BioMed Central Ltd

See related research by lyengar et al., http://ccforum.com/content/13/4/R126

We read with interest the article by lyengar and colleagues [1] on the impact of standardized implementation of medical emergency teams (METs) for the early identification and management of acutely deteriorating patients on the ward. The vast majority (88\%) of all preventable adverse events were classified as 'therapeutic errors'. The authors have to be commended for their proactive patient safety approach by implementation of a standardized method for root cause analysis and classification of preventable adverse events.

We and others have recently proposed an alternative model to the MET, namely one based on defined clinical triggers to initiate a rapid response escalation [2-4]. A clinical triggers system overcomes the 'classic' limitations of the MET system, as related to an overuse of resources and the fragmentation of patient care. The clinical triggers program established at Denver Health Medical Center involves a standardized 'afferent' limb of patient identification based on objective, physiological response triggers for a rapid response escalation. The 'efferent' limb is provided by the designated primary house staff team caring for the individual patient $[2,3]$.

While the present study [1] was not designed to address issues related to response system modalities, the root cause analysis by lyengar and colleagues supports the rationale of a clinical triggers-based response system. As such, the therapeutic errors identified as the major determinant of preventable adverse events [1] are likely recognized and corrected in a more accurate and timely fashion by a team of providers associated with the continuum of care, as opposed to a MET, which involves people who are unfamiliar with patients' pertinent medical conditions. These aspects should be taken into consideration in the ongoing debate and controversy about safety and efficiency of the 'perfect' rapid response system [5].

\section{Authors' contributions}

Both authors contributed equally to the design and writing of this letter.

\section{Competing interests}

The authors declare that they have no competing interests with regard to this manuscript.

\section{References}

1. lyengar A, Baxter A, Forster AJ: Using Medical Emergency Teams to detect preventable adverse events. Crit Care 2009, 13:R126.

2. Moldenhauer K, Sabel A, Chu ES, Mehler PS: Clinical triggers: an alternative to a rapid response team. J Comm J Qual Patient Saf 2009, 35:164-174.

3. Stahel PF, Smith WR, Clarke TJ, Mehler PS. [Patient safety in surgery: what lessons can we learn from the current US-standards?] Periop Med 2009, 1:34-43.

4. Cherry K, Martinek J, Esleck S, Ivory A, Logan R, Ward J: Developing and evaluating a trigger response system. $J$ Comm J Qual Patient Saf 2009, 35:331-338.

5. Sirio CA: Clinical triggers or rapid response teams: does the emperor need "new" clothes? J Comm J Qual Patient Saf 2009, 35:162-163.

MET = medical emergency team. 